\title{
Low activation of Insulin-like Growth Factor 1-Receptor (IGF1R) is associated with local recurrence in early breast carcinoma
}

\author{
Gloria Peiró · Susana Benlloch · Laura Sánchez-Tejada · Encarna Adrover · \\ Enrique Lerma · Francisca M. Peiró · José Sánchez-Payá · F. Ignacio Aranda
}

Received: 23 March 2008/Accepted: 15 July 2008/Published online: 6 August 2008

(C) Springer Science+Business Media, LLC. 2008

\begin{abstract}
Background The predictive value of IGF1R on local recurrence in invasive breast carcinoma $(\mathrm{BC})$ is not well known. Methods In a series of 197 lymph-node negative $\mathrm{BC}$ patients treated with breast-conserving surgery and radiation therapy, we performed immunohistochemistry for $\alpha$-IGF1R, $\beta$-IGF1R (phosphorylated/active form) and Estrogen/Progesterone receptors. We further evaluated the IGF1R mRNA expression by quantitative RT-PCR and $I G F 1 R$ mutations by direct DNA sequencing (exons 19 and 21 ) in 85 primary BC ( 42 control cases, 31 with local recurrence and 12 with distant metastasis) and in 31 local recurrences. Unconditional logistic regression analyses were performed to identify risk factors for recurrence. Results Local recurrences were associated with high-grade tumors, PR-negative and low active-IGF1R, which emerged as independent breast relapse predictors by multivariate analysis. Conclusion Patients with early BC
\end{abstract}

G. Peiró $(\bowtie) \cdot$ S. Benlloch · L. Sánchez-Tejada

Research Unit, Hospital General Universitari d'Alacant,

c/ Pintor Baeza s/n, 03010 Alacant, Spain

e-mail: peiro_glo@gva.es

E. Adrover

Department of Clinical Oncology, Hospital General Universitari

d'Alacant, Alacant, Spain

E. Lerma

Pathology Department, Hospital de la Santa Creu i Sant Pau,

Barcelona, Spain

F. M. Peiró · F. I. Aranda

Department of Pathology, Hospital General Universitari

d'Alacant, Alacant, Spain

J. Sánchez-Payá

Department of Epidemiology, Hospital General Universitari

d'Alacant, Alacant, Spain treated with lumpectomy and radiation who have lowgrade tumors and favorable markers (increased content of active IGF1R and PR-positive) have a low risk of local recurrence. Therefore, do not benefit from a boost dose on the surgical scar.

Keywords Early breast carcinoma $\cdot$ IGF1R $\cdot$ mRNA . Mutation

\section{Introduction}

Breast conservation has become standard treatment for patients with $\mathrm{BC}$ in early stage (I-II), although local recurrence (LR) occurs in 6-20\% of patients, mainly in those without complementary radiation therapy (RT) [1-3]. Among the clinical-pathological factors determinants of risk for LR take into account the young age ( $<35$ years) of the patients, pre-menopausal status, high histological grade, lymph-vascular invasion (LVI), multicentricity, presence of an extensive in situ component (EIC), margins status and the use of adjuvant therapy with hormone blockade and/or RT [4-6]. About 20-40\% of LRs have been associated with poorer outcome [3]. Therefore, the early identification of those patients at a high risk is important for an adequate treatment.

Currently, in $\mathrm{BC}$, there has been growing interest in identifying genetic factors that may influence the natural history and the response to treatment. Among them, the IGF1R pathway has been implicated in the initiation and progression of this neoplasia [7]. IGF1R is a glycosylated heterotetramer composed of two extracellular $\alpha$-subunits and two transmembrane $\beta$-subunits containing tyrosine kinase (TK) domains involved in signal transduction. The intracellular region of the $\beta$-subunit has a binding site for 
phosphorylation substrates at tyrosine residue 950, an ATP-binding at lysine 1003, a TK domain with three critical tyrosines (positions 1131, 1135 and 1136); and several tyrosines in the C-terminal domain (positions 1250 , 1251 and 1316) [8]. Binding of the ligand to the $\alpha$-subunit leads to autophosphorylation/stimulation of the $\beta$-subunit intrinsic TK activity, which in turn induces activation of phosphoinositide $3^{\prime}$-kinase (PI3K)/Akt pathway, blocking apoptosis and activating cellular proliferation [9]. Experimental models have revealed several receptor-dependent functions: DNA synthesis (TK domain), apoptosis and metastasis (TK and C-terminal domains), migration/invasion (TK enhanced through Tyr1250/1251) [10-13] and radioresistance mediation (Tyr1251) [14].

Elevated IGF1R protein levels have been documented in various human malignancies [15, 16]. Overall, IGF1R overexpression occurs between $40 \%$ and $82 \%$ of BC [1723]. Except for the well established correlation with ER status, its association with other prognostic parameters is still insufficiently documented [24-27]. On the other hand, the importance of IGF1R with respect to tumor control and response to therapy $[14,28]$ or survival $[20,21]$ is unclear. Currently, in lymph-node negative (LNN) BC patients, there are limited data evaluating the IGF1R protein receptor [17, 29, 30] and mutational status [14] and no previous studies have analyzed the relationship of IGF1R activation and mRNA levels with the risk of development of LR in patients with BC. So far, no data is available regarding a comprehensive analysis of IGF1R in primary breast tumors and their corresponding LR.

The present study was designed to examine the correlation of IGF1R protein expression and activation, IGF1R mRNA levels, and the presence of $I G F 1 R$ mutations with the risk of LR in a series of primary LNNBC treated with breast-conserving surgery (CS) and RT. IGF1R results in primary tumors that locally recurred were compared with those in their corresponding LR specimen. All the data are presented following the recommendations for tumor marker prognostic studies (REMARK) [31].

\section{Materials and methods}

Archival cases of LNNBC in stage I-II from 197 patients treated with CS and RT were retrieved from the archives of the Department of Pathology at the Universitary General Hospital of Alicante, from the period of January 1990 to December 1999. All had undergone a complete gross excision of the primary tumor and axillary lymph nodes dissection, with a minimum of five nodes removed.

Post-lumpectomy RT was mandated and a total dose of 50 Gy to the tumor bed was given. Patients with ER and/or PR-positive tumors received tamoxifen for 5 years.
Furthermore, patients with high risk factors (young age, high grade or ER/PR-negative tumors) were treated with systemic chemotherapy (CT) with six cycles of cyclophosphamide, methotrexate and 5-fluoroucil (CMF) or four cycles of doxorubicin plus cyclophosphamide (AC) after surgery. None received taxanes, trastuzumab (Hercep$\operatorname{tin}^{\mathrm{TM}}$ ) or aromatase inhibitors.

LR was defined as any recurrent infiltrating tumor at or near the primary site of the ipsilateral breast (parenchyma or skin).

Pathologic review was performed in all cases by two of the pathologists (G. Peiró, E. Lerma and F. I. Aranda) without knowledge of the outcome. Tumor size was determined by either gross or microscopic examination, histologic classification according to the World Health Organization (WHO) criteria, and histologic grade based on the Elston method [32]. Additional histologic features recorded were: presence of $\mathrm{LVI}$, necrosis $(\geq 5$ necrotic cells), and intraductal component (absent, $<25 \%$ or $\geq 25 \%$ ). Pathological margins were classified as negative (inked margin $>5 \mathrm{~mm}$ from the invasive component), close $(0.1-5 \mathrm{~mm}$ ), positive (at the inked margin or $<0.1 \mathrm{~mm}$ ) and indeterminate (biopsy not inked or non-valuable). The most representative area of the infiltrating tumor was selected for the tissue microarray (TMA) construction (Beecher Instruments; Silver Spring, MD) with $0.6 \mathrm{~mm}$ cores.

\section{Immunohistochemistry}

TMA sections 2-4 $\mu \mathrm{m}$ thick were mounted on poly-Llysine-coated slides (DakoREAL ${ }^{\mathrm{TM}}$, Glostrup, Denmark), deparaffinized and subjected to heat-induce epitope retrieval in $0.1 \mathrm{M}$ sodium citrate buffer ( $\mathrm{pH} 9$ ).

IGF1R protein status was analyzed by using a mouse polyclonal IGF1R $\alpha$-subunit (1:200 for $1 \mathrm{~h}$ at RT; Neomarkers) and the phosphorylated (active) form of IGF1R $\beta$ subunit (p-IGF1R) (phospho-IGF1R (Tyr1131)/Insulin receptor (Tyr1146); rabbit polyclonal Ab; Cell Signaling; 1:80; overnight at $4^{\circ} \mathrm{C}$ ). IHC assays were carried out in serial sections using the EnVision ${ }^{\mathrm{TM}}$ detection system peroxidase/DAB+, Rabbit/Mouse by using a TechMate 500-staining automat (Dako, Glostrup, Denmark). The staining (membranous and/or cytoplasmic) was semiquantitatively scored according to the percentage of positive tumor cells and intensity (from 0 to 3+) (score 0-300). For ER/PR, antibody characteristics, methodology and scores have been previously described [33].

\section{Molecular analyses}

We studied 116 tumor samples including $31 \mathrm{LR}$ and 85 primaries BC (42 without recurrence-control cases matched for histologic grade-31 with LR and 12 with DM). 
From 2 to 3 paraffin-embedded cylinders ( $0.6 \mathrm{~mm}$-thick) from pre-selected tumor areas, we extracted genomic DNA with QIAmp DNA miniKit, and isolated total RNA by handling RNeasy FFPE Kit (QIAgen, Hilden, Germany).

PCR amplification was performed in 25- $\mu$ l-reaction volume containing $1.25 \mathrm{mM} \mathrm{MgCl}_{2}, 0.2 \mu \mathrm{M}$ of each primer, $0.04 \mathrm{U} / \mu \mathrm{l}$ HotStar Taq polymerase (QIAgen) and $3 \mu \mathrm{l}$ of extracted DNA. PCR reactions were amplified for 35 cycles with an anneling temperature of $58^{\circ} \mathrm{C}$. The primer sets were obtained from RefSec DNA NM000875.2, designed with Primer3 (TIB MOLBIOL Syntheselabor, Berlin). They were as follows: (a) TK domain IGF1R (exon 19): IGFIR $F w 5^{\prime}$ TGTAGGGTCCTCTGCTGTGA-3' IGF1R, Rv 5'-ACCTTTA CTGCATTGCCAGC-3'. (b) C-terminal domain IGF1R (exon 21): IGF1R Fw 5'-GGCTGCAGGTTTGAACTGAT-3' IGFIR Rv 5'-CCAGAGAACATGGAGAGCGT-3'. The PCR products were purified by EXOSAP (Amersham Life Science Inc.). PCR amplicons were double strand sequenced using the ABI Prism BigDye Terminator v3.1 Cycle Sequencing kit (Applied Biosystems, Foster City, CA) and ABI Prism 310 automated sequencer. RT-PCR was performed in $20 \mu$ reaction volumes with random hexamer priming, $10 \mu \mathrm{l}$ of extracted RNA and High Capacity cDNA Reverse Transcription Kit (Applied Biosystems Inc, Santa Clara, CA). cDNA was diluted to 1:5 volume and $2.5 \mu \mathrm{l}$ of cDNA was amplified in a $12.5-\mu 1$ reaction volume for 40 cycles of RT-PCR using Taqman Universal PCR Master Mix and TaqMan $^{\circledR}$ Gene Expression Assays of IGF1R hCG1640727, $\beta$-glucuronidase (GUSB) hCG18478 and glyceraldehyde-3-phosphate dehydrogenase (GAPDH) hCG2005673 in the ABI Prism 7500 System (Applied Biosystems) in triplicate. RT minus controls and two commercial positive controls (total human and BC RNA) were included.

IGF1R quantification was normalized to GUSB and GAPDH genes, which are known to be relatively invariant. Since both were highly correlated (Spearman rank correlation coefficient: $r=0.82 ; P<0.000)$, all the results were normalized to GUSB. Relative mRNA expression levels were carried out using the $\Delta \Delta \mathrm{C}_{\mathrm{T}}$ method. The calibrator was a pool of 10 healthy breast tissue samples (mean $\Delta \Delta \mathrm{C}_{\mathrm{T}}$ $=1.293 ; \mathrm{SD} \pm 0.298)$

\section{Statistical analyses}

The chi-square or Fisher' tests were used, as appropriate, to determine the statistical significance of the qualitative results. Non-parametric Spearman's correlation test was used to determine the relationship between IGF1R protein and mRNA, and Mann-Whithney or Kruskal-Wallis test for the expressions' differences between pathologic features.

Multivariate analysis (unconditional logistic-regression model) was performed to determine the independent effect of the prognostic variables by comparing the group of patient with no recurrence with the group with LR. A variable's effect on LR was estimated by the model's odds ratio (OR), and a $95 \%$ confidence interval $(95 \% \mathrm{CI})$ was calculated for each OR. $P$ values $<0.05$ were considered statistically significant.

\section{Results}

Among our series of 197 LNNBC patients, 33 (16.8\%) had LR and $16(8.1 \%)$ DM. Patients' ages ranged from 23 to 88 years (average 52 years). Median follow-up was 100 months (range 16-234 months). The median time to LR was 50 months (range 7-201 months) and to metastasis 52 months (range 14-142 months).

Table 1 shows the distribution of the tumors in relation to clinical-pathologic features and development of LR/DM. Mean tumor size was $16 \mathrm{~mm}(\mathrm{SD} \pm 6.90 \mathrm{~mm})$. They were predominantly of ductal type $(98 \%)$, higher grade (148/ $197 ; 75 \%),<25 \%$ of DCIS $(165 / 197,84 \%)$ and no necrosis (119/197; 60\%) or LVI (140/197; 71\%). Microscopic margins were negative in $148(75 \%)$ tumors. Among the clinical-pathological features, histologic grade $(P=0.021)$ and the presence of an EIC $(P=0.047)$ correlated with the development of LR. ER and PR were positive in $75 \%$ and $65 \%$ of tumors, respectively. PR-negative tumors recurred locally more frequently than PR-positive (26\% vs. $11 \%$; $P=0.024)$, but no differences were observed for ER $(17 \%$ vs. $17 \% ; P=\mathrm{ns}$ ).

In addition to local RT, $45(22.8 \%)$ patients received systemic CT, $54(27.4 \%)$ patients tamoxifen and 98 (49.7\%) both CT + tamoxifen. Analysis according to systemic therapy groups showed non statistical differences regarding the total recurrence: $29 \%$ (13/45) for those with CT, $25.5 \%$ (25/98) when tamoxifen was added and $20.4 \%$ $(11 / 54)$ for those with only tamoxifen $(P=\mathrm{ns})$.

The median staining score for $\alpha$-IGF1R was 220 (range 90-300) and for p-IGF1R was 20 (1-60). For the purpose of the study, primary tumors were classified as having IGF1R low or high expression, using the median scores as cut-offs.[28]. We found not significant correlation between the $\alpha$-IGF1R and the risk of recurrence $(P=\mathrm{ns})$. However, lower p-IGF1R was associated with the presence of LR (31\% vs. $9 \% ; P=0.004)$.

$\alpha$-IGF1R levels were no different depending on the patients' age, presence of LVI or EIC $(P>0.05)$. Nevertheless, they were increased in low-intermediate grade tumors $(58 \%$ vs. $41 \% ; P=0.039)$, without necrosis $(62 \%$; $P=0.002)$, ER-positive $(62 \% ; P=0.001)$ or PR-positive (61\%; $P=0.018)$ and in association with p-IGF1R (71.4\%; $P=0.03)$. Similarly, increased $\mathrm{p}-\mathrm{IGF} 1 \mathrm{R}$ correlated with PR-positive cases (44\%; $P=0.02)$, and with low- 
Table 1 Characteristics of the patients and tumors in relation to clinicopathologic features, ER/PR and IGF1R expression

\begin{tabular}{|c|c|c|c|c|c|}
\hline & TOTAL cases $(\%)$ & no recurrence cases $(\%)$ & with LR cases $(\%)$ & with DM cases $(\%)$ & $P$ \\
\hline No. of cases & 197 & $148(75.1)$ & $33(16.8)$ & $16(8.1)$ & \\
\hline \multicolumn{6}{|l|}{ Age } \\
\hline$<40$ & $28(14)$ & $24(86)$ & $3(11)$ & $1(3)$ & \multirow[t]{2}{*}{ ns } \\
\hline$\geq 40$ & $169(86)$ & $124(73)$ & $30(18)$ & $15(9)$ & \\
\hline \multicolumn{6}{|l|}{ Menopausal status } \\
\hline Postmenopausal & $110(68)$ & $82(75)$ & $19(17)$ & $9(8)$ & \multirow[t]{2}{*}{ ns } \\
\hline Premenopausal & $53(32)$ & $42(79)$ & $5(10)$ & $6(11)$ & \\
\hline \multicolumn{6}{|l|}{ Tumor size } \\
\hline $5-20 \mathrm{~mm}$ & $149(76)$ & $111(77)$ & $24(16)$ & $11(7)$ & \multirow[t]{2}{*}{ ns } \\
\hline $21-50 \mathrm{~mm}$ & $48(24)$ & $34(71)$ & $9(19)$ & $5(10)$ & \\
\hline \multicolumn{6}{|l|}{ Histologic type } \\
\hline Ductal & $193(98)$ & $145(75)$ & $33(17)$ & $15(8)$ & \multirow[t]{2}{*}{ ns } \\
\hline Lobular & $4(2)$ & $3(75)$ & $0(0)$ & $1(25)$ & \\
\hline \multicolumn{6}{|l|}{ Histological grade } \\
\hline 1 & $49(25)$ & $44(90)$ & $4(8)$ & $1(2)$ & \\
\hline $2+3$ & $148(75)$ & $104(70)$ & $29(20)$ & $15(10)$ & 0.021 \\
\hline \multicolumn{6}{|l|}{$D C I S$} \\
\hline$<25 \%$ & $165(84)$ & $125(76)$ & $24(14)$ & $16(10)$ & \\
\hline$\geq 25 \%$ & $32(16)$ & $23(72)$ & $9(28)$ & $0(0)$ & 0.047 \\
\hline \multicolumn{6}{|l|}{ Necrosis } \\
\hline Absent & $119(60)$ & $91(76)$ & $21(17)$ & $7(6)$ & \\
\hline Present & 77 (40) & $57(74)$ & $11(14)$ & $9(12)$ & ns \\
\hline \multicolumn{6}{|l|}{$L V I$} \\
\hline Absent/ND & $140(71)$ & $109(78)$ & $22(16)$ & $9(6)$ & \\
\hline Present & $56(29)$ & $39(70)$ & $10(18)$ & $7(12)$ & ns \\
\hline \multicolumn{6}{|l|}{ Margins } \\
\hline Negative $(>5 \mathrm{~mm})$ & $148(75)$ & $111(75)$ & $25(17)$ & $212(8)$ & \\
\hline Close $(0.1-5 \mathrm{~mm})$ & $44(22)$ & 34 (77) & $7(16)$ & $3(7)$ & \\
\hline Positive $(<0.1 \mathrm{~mm})$ & $5(3)$ & $3(60)$ & $1(20)$ & $1(20)$ & ns \\
\hline \multicolumn{6}{|l|}{$E R$} \\
\hline Negative & $47(24)$ & $34(72)$ & $8(17)$ & $5(11)$ & \\
\hline Positive & $145(76)$ & $110(76)$ & $24(17)$ & $11(7)$ & ns \\
\hline \multicolumn{6}{|l|}{$P R$} \\
\hline Negative & $68(35)$ & $45(66)$ & $18(26)$ & $5(7)$ & \\
\hline Positive & $125(65)$ & $100(80)$ & $14(11)$ & $11(9)$ & 0.024 \\
\hline \multicolumn{6}{|l|}{$\alpha-I G F 1 R$} \\
\hline$\leq 220$ & $80(48)$ & $56(70)$ & $14(18)$ & $10(12)$ & \\
\hline$>220$ & $85(51)$ & $64(75)$ & $17(20)$ & $4(5)$ & ns \\
\hline \multicolumn{6}{|l|}{$p-I G F 1 R$} \\
\hline$\leq 20$ & $71(52)$ & $42(59)$ & $22(31)$ & $7(10)$ & \\
\hline$>20$ & $66(48)$ & $55(83)$ & $6(9)$ & $5(8)$ & 0.004 \\
\hline
\end{tabular}

* $\chi^{2}$ test; LVI, lymph-vascular invasion; ND, non definitive; ns, not significant; DCIS, ductal carcinoma in situ

intermediate grade $(63 \% ; P=0.044)$. Interestingly, further tumor stratification according to the IGF1R activity showed that those with ER/PR-negative recurred more frequently (38.5\%) than ER-positive/PR-negative (25\%) or ER-any/PR-positive $(3.8 \%)(P=0.004)$.
Table 2 summarizes the IHC and molecular characteristics of the controls and those with recurrences by IGF1R expression, IGF1R mRNA and IGFIR mutations. We observed no differences regarding the $\alpha$-IGF1R median score for control cases and tumors with DM or LR (240 vs. 
Table 2 IHC and molecular characteristics of the tumors according to the development of recurrence by IGF1R protein and activity, mRNA and mutations

$\alpha$-IGF1R median

score (P25-P75)

Primary tumors

Controls $(n=42)$

With DM $(n=12)$

$240(90-300)$

$120(80-300)$

With LR $(n=31)$

240 (60-300)

$P=\mathrm{ns}^{*}$

Local recurrences

$n=31$

$$
\begin{aligned}
& 240(60-285) \\
& r=0.432 ; P=0.019 * *
\end{aligned}
$$

p-IGF1R median
score (P25-P75)

$$
\begin{aligned}
& 30(1-80) \\
& 11(0.25-67) \\
& 4.5(0-20) \\
& P=0.008^{*}
\end{aligned}
$$

$$
\begin{aligned}
& 2(0-32.50) \\
& r=0.232 ; P=\mathrm{ns}^{* *}
\end{aligned}
$$

IGF1R mRNA median levels (P25-P75)

$I G F 1 R$

mutations no. $(\%)$

IHC, immunohistochemistry; DM, distant metastases; LR, local recurrence; * Kruskall-Wallis test; ** Spearman correlation test for the tumors with LR and their corresponding LR

120 vs. 240 , respectively; $P=$ ns; Kruskall-Wallis test). However, we found significantly lower median levels of p-IGF1R (active form) in those with LR (median $=4.5$; P25-P75 = 0-20) than with DM (median = 11; P25-P75 = 0.25-67) or controls (median $=30 ; \mathrm{P} 25-\mathrm{P} 75=1-80$ ) ( $P=0.008$; Kruskall-Wallis test). Further analysis of the primary tumors with LR with their corresponding recurrence samples showed only a positive correlation for $\alpha$-IGF1R (Spearman correlation coefficient: $r=0.432$; $P=0.019)$.

The median relative IGF1R mRNA for primary tumors ( $n=85$ ) was 2.57. Stratification of the data showed no differences in controls cases and those with DM or LR (median $=2.55$ vs. 3.65 vs. 2.54 , respectively; $P=\mathrm{ns}$; Kruskall-Wallis test). Moreover, no correlation was found between the mRNA levels in primary tumors with their corresponding LR (median $=1.22$ ) (Spearman correlation coefficient: $r=0.027 ; P=\mathrm{ns}$ ) (Table 2). For the purpose of the study, we categorized the mRNA level of the tumors into two groups: low (median $<2.57$ ) versus high (median $\geq 2.57$ ) expression. We observed only a trend between the mRNA high expression and the presence of LVI (17/28, $61 \% ; P=0.16)$. Moreover, IGF1R mRNA was higher in ER-positive than in ER-negative tumors $(61 \%$ vs. $15 \% ; P$ $<0.000)$, which was similar for PR $(61 \%$ vs. $33 \% ; P=$ $0.014)$. However, no association was found with $\alpha$-IGF1R or p-IGF1R $(P=\mathrm{ns})$.
Among the 116 tumors (42 controls, 31 with LR, 12 with DM, and $31 \mathrm{LR}$ ) analyzed for mutations in the $\beta$ subunit (TK-domain at positions Tyr1131, Tyr1135 and Tyr1136; and C-terminal domain at positions Tyr1250 and Tyr1251), we only detected IGFIR mutations at Tyr1131 (A3532G) in six primary tumors (three with LR and in three controls) and in one LR $(P=$ ns) (Table 3 and Fig. 1). Interestingly, five out of the six $(83 \%)$ mutated tumors showed $\alpha$-IGF1R overexpression, but this was only marginally significant $(P=0.079$; Fisher test $)$. No differences were observed regarding p-IGF1R $(3 / 6 ; 50 \% ; P=\mathrm{ns})$ or IGF1R mRNA $(3 / 6 ; 50 \% ; P=\mathrm{ns})$.

Only variables that were statistically significant in the univariate analysis (histologic grade, EIC, PR and p-IGF1R expression) were combined in the multivariate analysis. The results showed as independent breast relapse predictors the histologic grade (OR, 3.1; $P=0.04)$, the levels of $\mathrm{p}$ IGF1R (OR, 4.2; $P=0.004)$ and PR status (OR, 2.8; $P=$ $0.02)$, and as a trend with the presence of an EIC (OR, 2.1; $P=0.10)$ (see Table 4).

\section{Discussion}

Over the past years there has been a large effort to identify predictive markers associated with LR [3-6]. 20-40\% of LRs are associated with DM and a worse prognosis. LR in
Table 3 Characteristics of primary tumors $(n=6)$ and LR $(n=1)$ with $I G F 1 R$ mutation (Tyr1131)

\begin{tabular}{llllccc}
\hline Case no. & Grade & Size $(\mathrm{Mm})$ & $\alpha$-IGF1R score & p-IGF1R score & IGF1R mRNA levels & LR \\
\hline 6 & 2 & 32 & 300 & 160 & 1.730 & No \\
15 & 3 & 20 & 300 & 60 & 0.417 & No \\
16 & 3 & 18 & 300 & 90 & 12.933 & No \\
74 & 2 & 22 & 285 & 0 & 15.889 & Yes \\
109 & 3 & 18 & 300 & 2 & 4.329 & Yes \\
164 & 3 & 15 & 60 & 5 & 2.553 & Yes \\
LR & 2 & 25 & 3 & 1 & 1.664 & \\
\hline
\end{tabular}


Fig. 1 IGFIR mutation at Tyr1131 (A3532G)

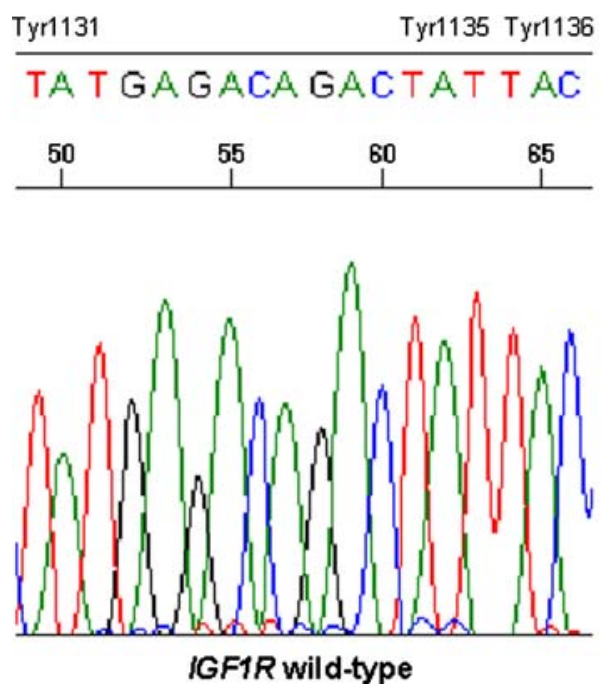

$\frac{\text { Tyr1131 }}{\text { TNT GAG ACA GACTAT TAC }}$

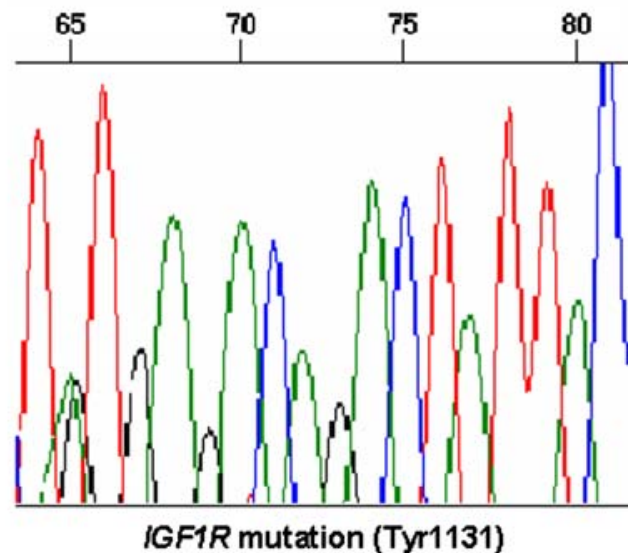

Table 4 Multivariate analysis (unconditional logistic-regression model) of histological and biological factors

\begin{tabular}{lllll}
\hline Variables & $\beta$ & Odds ratio & $95 \%$ CI & $P$ \\
\hline Histol grade & 1.32 & 3.1 & $1.0-9.1$ & 0.04 \\
EIC & 0.75 & 2.1 & $0.8-5.2$ & 0.10 \\
PR & 1.06 & 2.8 & $1.1-7.1$ & 0.02 \\
p-IGF1R & 1.45 & 4.2 & $1.5-11.7$ & 0.004 \\
\hline
\end{tabular}

EIC, extensive intraductal component; PR, progesterone receptor; p-IGF1R, phosphorylated Insulin-like Growth Factor 1-Receptor

not uniformly defined in the articles reviewed; in some of them, all the lumpectomy area is considered as target volume for both boost dose or LR. Actual criteria are more restricted to $3 \mathrm{~cm}$ from the surgical margins. Also, true differences exist between early recurrence and resistance to $\mathrm{RT}$, the last being defined as that which occurs in the first 12 months after finishing local treatment and is always associated with a worse prognosis. Later relapses on the other hand, occur beyond 1 year and are more dependent on medical treatments. In the present series of LNNBC treated with CS followed by RT and systemic treatment with tamoxifen and/or chemotherapy, histologic grade and the presence of an EIC correlated with LR risk. In addition, patients with PR-negative tumors showed the highest rate, supporting that ER-positive/PR-negative and ER/PR-positive $\mathrm{BC}$ are clinically and biologically distinct tumors [34]. However, no differences were observed for younger aged, positive/close margin of resection, LVI, or ER status. Further analysis according to systemic therapy groups showed no differences regarding the total recurrence. Randomized trials have shown not only decreased LR with RT but also an improvement in overall survival [1] being the magnitude greater with the combination of systemic therapy $[2,3,35]$. These analyses were out of the scope of the current study.
Similar to prior investigators in patients with lymph nodes-positive BC, we found increased IGF1R expression and activity more frequently in less aggressive tumors such as those with low-intermediate grade and no necrosis [18, 20, 27, 28]. Nevertheless, IGF1R may have still some relevance in aggressive triple-negative (ER/PR and HER2) tumors [36] and in ER-negative patients implying a shortened disease-free survival [30]. In our study, we found only a positive correlation of $\alpha$-IGF1R expression in primary tumors with their corresponding LR specimen, suggesting no changes of the receptor level when tumors recur.

Of note, IGF1R sends contradictory signals to cells depending on the availability of substrates. In the absence/ low concentration of IRS-1, IGF1R induces cell differentiation, but when both are expressed, it has the ability to transform cells [9]. Schnarr et al. reported high levels of IRS-1 and IGF1R in breast tissues, in well-moderately differentiated carcinomas, but at low levels in poorly differentiated BC in agreement with our data [20]. Usually higher expression of IGF1R, autophosphorylation and kinase activity is detected in malignant than in normal breast tissue [19].

IGF1R and ER are frequently co-expressed and the two signalling systems are engaged in a cross-talk that regulates $\mathrm{BC}$ proliferation, protection from apoptosis and metastasis $[9,26]$. We observed that tumors containing lower active IGF1R and PR-negative showed higher rates of LR, supporting their protective effect [20] and the interaction between both receptors [23, 25, 27, 37]. In agreement, Gee et al. [28] showed increased expression $(\alpha$-IGF1R) and activation (polyclonal antibody detecting Y1316 IGF-1R phosphorylation) in $\mathrm{BC}$ with good prognostic factors, and that was associated with the relevance to growth of tamoxifen-responsive disease, as seen by others [17, 29].

In contrast to our data, Turner et al. reported an association of IGF1R overexpression with higher LR which 
was attributed to radiation resistance. Moreover, they found no association with ER/PR status, overall and disease-free survival, or axillary lymph-node involvement [14]. The discrepancies may be, on the one hand, due to the selection of patients. In fact, Turner presents an ancient series of early breast cancers with less than $30 \%$ of the patients treated with hormonotherapy according to old medical guidelines; we are led to suppose that at least $2 / 3$ of the patients studied should be ER/PR positive and therefore were undertreated and did not benefit from chemoprevention with tamoxifen (radiation therapy cannot prevent progression from premalignant to malignant (in situ and infiltrating) lesions. On the other hand, the IHC assay results may not be comparable since a different antibody (against the IGF1R $\beta$-subunit) of ours (against the phosphorylated-active form-of IGF1R $\beta$-subunit and the IGF1R $\alpha$-subunit) and scoring system were applied.

In the current series, increased IGF1R mRNA expression was seen in neoplastic tissues, predominantly in ER/ PR-positive tumors [23]. In contrast, Voskuil et al. reported higher levels in normal breast than in tumor tissue, and higher in tissue from women with a family history of BC [38]. In line with Al Sarakbi et al, we found no association with other clinical-pathological features [22]. In addition, we were not able to demonstrate in our cases any relationship between the mRNA levels in primary tumors with the corresponding LR as well as with the risk of LR/DM. To date, no other previous studies have quantitatively evaluated and compared the IGF1R mRNA in breast tumors tissues and recurrences for a comparison of our results.

Prior mutational analysis studies have suggested that signals derived from both regions of the IGF1-receptor cooperate to enhance metastasis. Experimental studies in M-27 cells (a clonal subline of the Lewis lung carcinoma) by Brodt using site-directed mutagenesis showed that mutation of any two of the tyrosines or a triple mutation in the TK domain abrogated the transformed phenotype and blocked metastasis [13]. However, a receptor mutated in the TK domain could still provide cell survival signals in a B cell lymphoma or a fibroblastic cell model as long as the tyrosines in positions 1250 and 1251 remained intact [39]. Consistently, among our cases with $I G F 1 R$ mutations, all at Tyr1131 (A3532G), none developed DM, but three had LR and three did not recur. Only one LR specimen showed mutation that was not present in the corresponding primary tumor. Moreover, no mutations were detected in the C-terminal domain that could explain the relationship between LR and radioresistance reported in a previous study [14]. Turner's in vitro analyses based on the study of mouse fibroblasts cell lines (BALB/c3T3) to clarify radioresistance cannot parallel with human breast cancer models where a close cross-talk between IGF1R and ER signalling, growth factors, tumor suppressor genes and apoptosis-involved proteins is present [14]. The IGF1R can probably utilize several distinct signalling pathways that may either involve, or to be independent of, the known receptor substrates to lead a determinate cellular response [39]. Therefore, the differences among the above reports may reflect unique properties of the different cell types used in these studies [40].

Of interest, recent studies suggest that gene-expression signature can be more powerful to predict LR after CS [41] metastasis and survival [42] and response to tamoxifen [43] than the standard clinical-pathological criteria. Nevertheless, IGF1R was not included in these studies.

In summary, our results indicate that in LNNBC patients treated with CS, local RT and adjuvant chemo- and/or hormone therapy, those with tumors showing low IGF1R activation, PR-negative and high grade have an increased risk of LR, which could be partially related with tamoxifen responsiveness. Apparently, IGF1R protein, mRNA or gene status do not seem major contributors to the radioresistance. Therefore, the subset of patients with low-grade tumours and favourable markers (increased content of active IGF1R and PR-positive) does not benefit from additional boost dose over the scar to prevent LRs. Nonetheless, more clinical research should be done to confirm our results and to elucidate unresolved questions regarding the complex mechanisms involved in LR in which IGF1R is involved as well as its prognostic value in $\mathrm{BC}$ patients in early stage.

Acknowledgments Supported by Project Grant FIS 03/1411 from the Fondo de Investigación Sanitaria, Ministry of Health (Spain). We thank Cristina Albaladejo, María D. Durán and Estefanía Rojas for their technical assistance; and Doreen Dennecker for the preparation of the manuscript.

\section{References}

1. Clarke M, Collins R, Darby S et al (2005) Effects of radiotherapy and of differences in the extent of surgery for early breast cancer on local recurrence and 15-year survival: an overview of the randomised trials. Lancet 366:2087-2106

2. Early Breast Cancer trialists' Collaborative Group (EBCTCG) (2005) Effects of chemotherapy and hormonal therapy for early breast cancer on recurrence and 15-year survival: an overview of the randomised trials. Lancet 365:1687-1717. doi:10.1016/S01406736(05)66544-0

3. Livi L, Paiar F, Saieva C et al (2007) Survival and breast relapse in 3834 patients with T1-T2 breast cancer after conserving surgery and adjuvant treatment. Radiother Oncol 82:287-293. doi: 10.1016/j.radonc.2006.11.009

4. Connolly JL, Boyages J, Nixon AJ et al (1998) Predictors of breast recurrence after conservative surgery and radiation therapy for invasive breast cancer. Mod Pathol 11:134-139

5. Peiro G, Bornstein BA, Connolly JL et al (2000) The influence of infiltrating lobular carcinoma on the outcome of patients treated with breast-conserving surgery and radiation therapy. Breast Cancer Res Treat 59:49-54. doi:10.1023/A:1006384407690 
6. Neri A, Marrelli D, Rossi S et al (2007) Breast cancer local recurrence: risk factors and prognostic relevance of early time to recurrence. World J Surg 31:36-45. doi:10.1007/s00268006-0097-2

7. Yakar S, Leroith D, Brodt P (2005) The role of the growth hormone/insulin-like growth factor axis in tumor growth and progression: lessons from animal models. Cytokine Growth Factor Rev 16:407-420. doi:10.1016/j.cytogfr.2005.01.010

8. Adams TE, Epa VC, Garrett TP, Ward CW (2000) Structure and function of the type 1 insulin-like growth factor receptor. Cell Mol Life Sci 57:1050-1093. doi:10.1007/PL00000744

9. Werner H, Maor S (2006) The insulin-like growth factor-I receptor gene: a downstream target for oncogene and tumor suppressor action. Trends Endocrinol Metab 17:236-242. doi: 10.1016/j.tem.2006.06.007

10. Kato H, Faria TN, Stannard B et al (1994) Essential role of tyrosine residues 1131,1135 , and 1136 of the insulin-like growth factor-I (IGF-I) receptor in IGF-I action. Mol Endocrinol 8:4050. doi:10.1210/me.8.1.40

11. Blakesley VA, Kalebic T, Helman LJ et al (1996) Tumorigenic, mitogenic capacities are reduced in transfected fibroblasts expressing mutant insulin-like growth factor (IGF)-I receptors. The role of tyrosine residues 12501251 , and 1316 in the carboxyterminus of the IGF-I receptor. Endocrinology 137:410-417. doi: 10.1210/en.137.2.410

12. Hongo A, Yumet G, Resnicoff M et al (1998) Inhibition of tumorigenesis and induction of apoptosis in human tumor cells by the stable expression of a myristylated $\mathrm{COOH}$ terminus of the insulin-like growth factor I receptor. Cancer Res 58:2477-2484

13. Brodt P, Fallavollita L, Khatib AM et al (2001) Cooperative regulation of the invasive and metastatic phenotypes by different domains of the type I insulin-like growth factor receptor beta subunit. J Biol Chem 276:33608-33615. doi:10.1074/jbc. M102754200

14. Turner BC, Haffty BG, Narayanan L et al (1997) Insulin-like growth factor-I receptor overexpression mediates cellular radioresistance and local breast cancer recurrence after lumpectomy and radiation. Cancer Res 57:3079-3083

15. Ouban A, Muraca P, Yeatman T, Coppola D (2003) Expression and distribution of insulin-like growth factor-1 receptor in human carcinomas. Hum Pathol 34:803-808. doi:10.1016/S00468177(03)00291-0

16. Peiro G, Lohse P, Mayr D, Diebold J (2003) Insulin-like growth factor-I receptor and PTEN protein expression in endometrial carcinoma. Correlation with bax and bcl-2 expression, microsatellite instability status, and outcome. Am J Clin Pathol 120:78-85. doi:10.1309/C1KAH1PRL1UBW798

17. Papa V, Gliozzo B, Clark GM et al (1993) Insulin-like growth factor-I receptors are overexpressed and predict a low risk in human breast cancer. Cancer Res 53:3736-3740

18. Happerfield LC, Miles DW, Barnes DM et al (1997) The localization of the insulin-like growth factor receptor 1 (IGFR-1) in benign and malignant breast tissue. J Pathol 183:412-417 10.1002/(SICI) 1096-9896(199712)183:4<412::AID-PATH944> 3.0.CO;2-4

19. Resnik JL, Reichart DB, Huey K et al (1998) Elevated insulinlike growth factor I receptor autophosphorylation and kinase activity in human breast cancer. Cancer Res 58:1159-1164

20. Schnarr B, Strunz K, Ohsam J et al (2000) Down-regulation of insulin-like growth factor-I receptor and insulin receptor substrate-1 expression in advanced human breast cancer. Int J Cancer 89:506-513. doi:10.1002/1097-0215(20001120)89:6<506::AIDIJC7>3.0.CO;2-F

21. Shimizu C, Hasegawa T, Tani Y et al (2004) Expression of insulin-like growth factor 1 receptor in primary breast cancer: immunohistochemical analysis. Hum Pathol 35:1537-1542. doi: 10.1016/j.humpath.2004.09.005

22. Al Sarakbi W, Chong Y, Williams S et al (2006) The mRNA expression of IGF-1 and IGF-1R in human breast cancer: association with clinico-pathological parameters. J Carcinog 5:16. doi:10.1186/1477-3163-5-16

23. Chong YM, Colston K, Jiang WG et al (2006) The relationship between the insulin-like growth factor-1 system and the oestrogen metabolising enzymes in breast cancer tissue and its adjacent non-cancerous tissue. Breast Cancer Res Treat 99:275-288. doi: 10.1007/s10549-006-9215-y

24. Dupont J, Le Roith D (2001) Insulin-like growth factor 1 and oestradiol promote cell proliferation of MCF-7 breast cancer cells: new insights into their synergistic effects. Mol Pathol 54:149-154. doi:10.1136/mp. 54.3.149

25. Chan TW, Pollak M, Huynh H (2001) Inhibition of insulin-like growth factor signaling pathways in mammary gland by pure antiestrogen ICI 182, 780. Clin Cancer Res 7:2545-2554

26. Surmacz E, Bartucci M (2004) Role of estrogen receptor alpha in modulating IGF-I receptor signaling and function in breast cancer. J Exp Clin Cancer Res 23:385-394

27. Ueda S, Tsuda H, Sato K et al (2006) Alternative tyrosine phosphorylation of signaling kinases according to hormone receptor status in breast cancer overexpressing the insulin-like growth factor receptor type 1. Cancer Sci 97:597-604. doi: 10.1111/j.1349-7006.2006.00228.x

28. Gee JM, Robertson JF, Gutteridge E et al (2005) Epidermal growth factor receptor/HER2/insulin-like growth factor receptor signalling and oestrogen receptor activity in clinical breast cancer. Endocr Relat Cancer 12(Suppl 1):S99-S111. doi:10.1677/ erc. 1.01005

29. Bonneterre J, Peyrat JP, Beuscart R, Demaille A (1990) Prognostic significance of insulin-like growth factor 1 receptors in human breast cancer. Cancer Res 50:6931-6935

30. Railo MJ, von Smitten K, Pekonen F (1994) The prognostic value of insulin-like growth factor-I in breast cancer patients. Results of a follow-up study on 126 patients. Eur J Cancer 30A:307-311. doi:10.1016/0959-8049(94)90247-X

31. McShane LM, Altman DG, Sauerbrei W et al (2006) REporting recommendations for tumor MARKer prognostic studies (REMARK). Breast Cancer Res Treat 100:229-235. doi: 10.1007/s10549-006-9242-8

32. Elston CW, Ellis IO (1991) Pathological prognostic factors in breast cancer. I. The value of histological grade in breast cancer: experience from a large study with long-term follow-up. Histopathology 19:403-410. doi:10.1111/j.1365-2559.1991.tb00229.x

33. Peiro G, Adrover E, Aranda FI et al (2007) Prognostic implications of HER-2 status in steroid receptor-positive, lymph nodenegative breast carcinoma. Am J Clin Pathol 127:780-786. doi: 10.1309/FWHEQX6HB9190LVY

34. Arpino G, Weiss H, Lee AV et al (2005) Estrogen receptorpositive, progesterone receptor-negative breast cancer: association with growth factor receptor expression and tamoxifen resistance. J Natl Cancer Inst 97:1254-1261

35. Punglia RS, Morrow M, Winer EP, Harris JR (2007) Local therapy and survival in breast cancer. N Engl J Med 356:23992405. doi:10.1056/NEJMra065241

36. Lerma E, Peiro G, Ramon T et al (2007) Immunohistochemical heterogeneity of breast carcinomas negative for estrogen receptors, progesterone receptors and Her2/neu (basal-like breast carcinomas). Mod Pathol 20:1200-1207. doi:10.1038/modpathol. 3800961

37. Guvakova MA, Surmacz E (1997) Tamoxifen interferes with the insulin-like growth factor I receptor (IGF-IR) signaling pathway in breast cancer cells. Cancer Res 57:2606-2610 
38. Voskuil DW, Bosma A, Vrieling A et al (2004) Insulin-like growth factor (IGF)-system mRNA quantities in normal and tumor breast tissue of women with sporadic and familial breast cancer risk. Breast Cancer Res Treat 84:225-233. doi: 10.1023/B:BREA.0000019954.59130.d3

39. O'Connor R, Kauffmann-Zeh A, Liu Y et al (1997) Identification of domains of the insulin-like growth factor I receptor that are required for protection from apoptosis. Mol Cell Biol 17:427-435

40. Petley T, Graff K, Jiang W et al (1999) Variation among cell types in the signaling pathways by which IGF-I stimulates specific cellular responses. Horm Metab Res 31:70-76
41. Nuyten DS, Kreike B, Hart AA et al (2006) Predicting a local recurrence after breast-conserving therapy by gene expression profiling. Breast Cancer Res 8:R62. doi:10.1186/bcr1614

42. Wang Y, Klijn JG, Zhang Y et al (2005) Gene-expression profiles to predict distant metastasis of lymph-node-negative primary breast cancer. Lancet 365:671-679

43. Paik S, Shak S, Tang G et al (2004) A multigene assay to predict recurrence of tamoxifen-treated, node-negative breast cancer. N Engl J Med 351:2817-2826. doi:10.1056/NEJMoa041588 